\title{
Correction to: Eagle's Syndrome: A Diagnostic Challenge and Surgical Dilemma
}

\author{
Annuradha Dey ${ }^{1}$ (D) Srijon Mukherji ${ }^{1,2}$
}

Published online: 20 August 2020

(c) The Association of Oral and Maxillofacial Surgeons of India 2020

Correction to: J. Maxillofac. Oral Surg. https://doi.org/10.1007/s12663-020-01396-x

The article Eagle's Syndrome: A Diagnostic Challenge and Surgical Dilemma, written by Annuradha Dey and Srijon Mukherji, was originally published electronically on the publisher's internet portal (currently SpringerLink) on 26
June 2020 with open access. With the author(s)' decision to step back from Open Choice, the copyright of the article changed on 07 August 2020 to (c) The Association of Oral and Maxillofacial Surgeons of India 2020 and the article is forthwith distributed under the terms of copyright. The original article has been corrected.

The original article can be found online at https:// doi.org/10.1007/s12663-020-01396-X.

Annuradha Dey

deyannuradha@gmail.com

1 Calcutta Institute of Maxillofacial Surgery and Research, 200, Rajdanga, Nabapally, Kolkata, West Bengal 700107, India

2 Royal College of Surgeons, Edinburgh, Edinburgh, UK 